\title{
Operation of a Catalytic Reverse Flow Reactor for the Purification of Air Contaminated with Volatile Organic Compounds
}

\author{
L. VAN DE BELD and K. R. WESTERTERP*
}

\begin{abstract}
Chemical Reaction Engineering Laboratories, Department of Chemical Engineering, University of Twente, P.O. Box 217, NL-7500 AE Enschede, The Netherlands
\end{abstract}

\begin{abstract}
Catalytic oxidation in a reverse flow reactor is an attractive process for the decontamination of air polluted with volatile organic compounds (VOCs). In this paper several aspects of operating this type of reactor for air purification under strongly varying conditions will be discussed.

For a successful operation of such reactor a minimum amount of combustibles is required, and a simple theory is developed to predict this minimum value. This minimum amount is strongly influenced by the reaction kinetics, the heat transport in the packed bed and the adiabaticity of the reactor. To cope with a too low temperature level in the reactor for a complete conversion, an electrical heating device should be installed in the centre of the reactor bed to increase locally the temperature rapidly and efficiently. To control the maximum temperature in case of too high concentrations, extra air should be added to the feed.

L'oxydation catalytique dans un réacteur à écoulement inverse est un procédé intéressant pour la décontamination de l'air pollué par des composés organiques volatils (VOC). Dans cet article, plusieurs aspects du fonctionnement de ce type de réacteur pour la purification de l'air dans des conditions extrêmement variables seront analysés.

Pour le bon fonctionnement d'un tel réacteur, un apport minimum en combustible est nécessaire, et une théorie simple a été établie afin de prédire cette valeur minimum. Cet apport minimum est fortement influencé par la cinétique de la réaction, le transfert de chaleur dans le lit garni et l'adiabicité du réacteur. Pour éviter d'avoir une température trop basse dans le réacteur en vue d'une conversion complète, un dispositif de chauffage électrique doit être installé au centre du lit du réacteur afin d'augmenter localement la température de façon rapide et efficace. Pour contrôler la température maximum en cas de concentrations trop fortes, de l'air doit être ajouté à l'alimentation.
\end{abstract}

Keywords: catalytic combustion, reverse flow operation, air purification.

E xhaust air from laboratories or factory buildings can be contaminated with volatile organic compounds (VOCs). In order to reduce the emission of VOCs, a large number of methods are available. The economically most attractive method depends on the specific conditions in each case, including the concentration and nature of the contaminants and the flow rate. Moreover, the polluted air stream might show strong variations in flow rate as well as in concentration and chemical character of the pollutants. In the case of valuable contaminants, separation methods with recovery of the organic compounds might be considered. Examples in this area are membrane separation and pressure swing adsorption. These methods have in common that the contaminants are concentrated in the first step of the process. The second step is the recovery of the contaminants. Another group of purification methods is composed of destructive processes like thermal and catalytic combustion, which are non-selective. Many modifications or combinations are possible, as for example high-grade heat generation; see Anon (1993).

In Novosibirsk, Russia, some decades ago Boreskov and coworkers developed a new technology which also can be applied to air purification problems; see Boreskov et al. (1986). Their basic idea was that operating a reactor under transient conditions may improve its performance. In this particular case, unsteady-state conditions were created by periodically reversing the direction of the feed flow. After a large number of flow reversals a so-called Pseudo-Steady-State

\footnotetext{
*Author to whom correspondence may be addressed. E-mail address: K.R.Westerterp@ct.utwente.nl
}

(PSS) is achieved. The maximum temperature in the PSS remains constant and the heat of the reaction is removed by an increase in the temperature of the reactor outlet stream. The many benefits of operating a reactor under unsteadystate conditions have been summarized by Matros (1990). For the air purification process in particular, we can mention that an autothermal process is possible with very low concentrations of the contaminants and that the reactor can handle large fluctuations in inlet conditions of flow rate and concentration.

\section{Operation of a reverse flow reactor}

In this paper we will discuss different aspects of operating a reverse flow reactor (RFR) under industrial conditions; special attention is paid to the control of the system. For a proper operation of a RFR, a minimum amount of combustibles is required, and a simple method is presented for prediction of this minimum amount. This method provides insight into the key parameters which must be considered, e.g. When the objective is to lower the minimum amount of combustible required.

\section{MINIMUM OPERATING TEMPERATURE OF THE CATALYTIC BED}

As far as destructive air purification processes are concerned, high conversions of the contaminants to harmless products are required. To control the conversion in a catalytic incineration process, the key parameter is the temperature of the catalyst bed. Van de Beld et al. (1994c) developed a simple, empirical method to determine the minimum temperature $T_{99}$ which should be applied in the catalytic bed to obtain at 


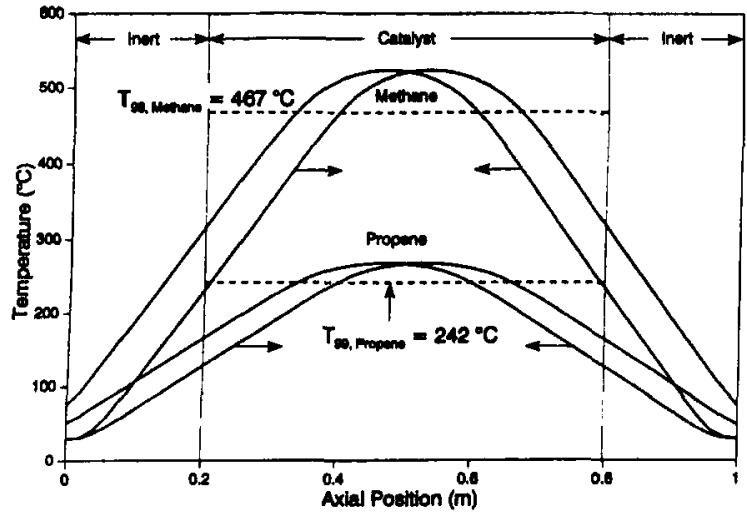

Figure 1 - Axial temperature profiles in the PSS for methane and propene, respectively. $t_{c}=200 \mathrm{~s} ; u_{g}=0.40 \mathrm{~m} / \mathrm{s} ; \Delta T_{\text {ad,methane }}=$ $18.8^{\circ} \mathrm{C} ; \Delta T_{\text {ad,propene }}=8.8^{\circ} \mathrm{C} ;$ conversion $=99 \%$.

least $99 \%$ conversion. An experiment is carried out as follows: the total hydrocarbon concentration in the reactor outlet is monitored continuously by means of a flame ionisation detector. The experiment is started at a bed temperature of around $100^{\circ} \mathrm{C}$. In about 20 to 30 minutes, the reactor is heated up to $600^{\circ} \mathrm{C}$. The result of an experiment is the total hydrocarbon concentration in the reactor outlet as a function of the temperature of the reactor bed. A reactor model has been developed yielding the following expression for $T_{99}$ (see Van de Beld et al., 1994c):

$$
T_{99}=\frac{E_{a c t}}{R} \frac{1}{\ln \left(0.217 k_{\infty} R T_{0} \tau_{0}\right)} \ldots \ldots \ldots \ldots \ldots
$$

To use this equation, knowledge of the kinetic parameters is needed, which in practice often are not available; even the nature of the contaminants might even be unknown: thus, it is hardly possible to estimate $T_{99}$ without experimental data. The experimentally determined $T_{99}$ will be the same for a reverse flow reactor provided the residence time of the gas phase in that reactor is the same (the gas velocity and the length of the catalyst bed might be different), so no information on the kinetics is needed. For a different residence time $\tau_{0}^{*}$ the corresponding $T_{99}^{*}$ can be calculated as follows:

$$
\frac{1}{T_{99}^{\circ}}=\frac{1}{T_{99}}+\frac{R}{E_{a c t}} \ln \left(\frac{\tau_{0}^{*}}{\tau_{0}}\right) \ldots \ldots \ldots \ldots \ldots \ldots
$$

In this expression, the activation energy is required, which also can be obtained adequately with the method mentioned; for details see Van de Beld et al. (1994c). The average temperature in the catalytic bed should be at least equal to $T_{99}$. This is illustrated in Figure 1 for simulations with methane and propene, respectively, where conditions are such that in the PSS just $99 \%$ conversion of the contaminant is obtained. Methane is very stable and the operating temperature needed is much higher than for propene. When these two components are jointly present in the feed, three (pseudo-)steady-states might be observed: 1 ) the entire catalyst bed is cold and total conversion is negligible; 2) the reactor operates at a higher temperature -and although it seems to work properly- only propene is converted; methane passes the catalyst bed unconverted; 3 ) the temperature is high enough for both components and the conversion is

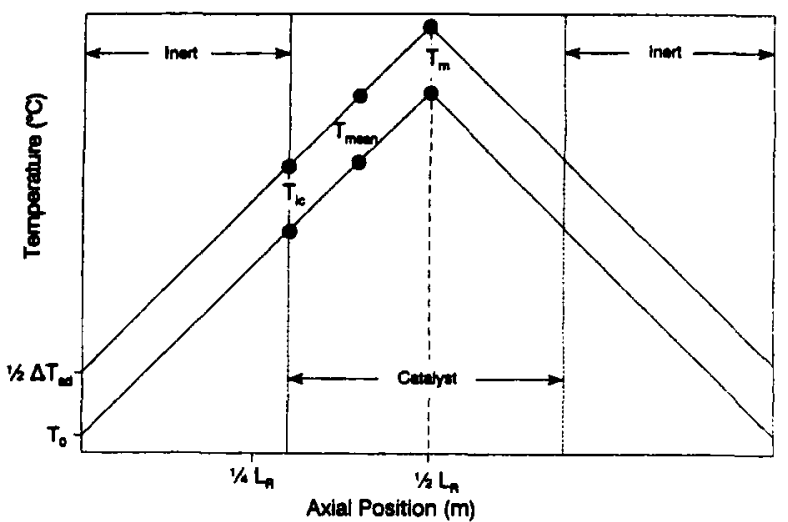

Figure 2 - Schematic representation of the method for the prediction of the minimum adiabatic temperature rise required for autothermal operation.

complete. The latter situation is the desired one, and the method we describe here can be a simple tool to determine the temperature level which should be maintained in the catalyst bed to ensure complete conversion of all contaminants.

\section{MINIMUM ADIABATIC TEMPERATURE RISE FOR AUTOTHERMAL OPERATION}

To ensure autothermal operation of the reactor with a high conversion of the contaminants, a minimum amount of combustibles is required in the feed. The heat released by the reaction compensates the heat removed from the reactor by the outlet stream and the heat losses. In the following section a simple theory is developed to predict the minimum amount required and how it can be influenced.

The minimum amount of combustibles required is represented by the required minimum adiabatic temperature rise $\Delta T_{a d, \min }$. As full conversion of the contaminants should have been achieved in the catalyst bed, the temperature in the reactor in the PSS should be above $T_{99}$. By model simulations it can be shown that the influence of the cycle period on $\Delta T_{a d, \min }$ is rather small, provided that it is not so large that all accumulated heat is removed from the reactor during a half-cycle. Therefore, for our analysis we will use a steadystate approximation (see Van de Beld and Westerterp, 1994a). To estimate the minimum adiabatic temperature rise $\Delta T_{\text {qd, min }}$ it is assumed the temperature in the reactor increases until the middle plane of the reactor and then decreases with the same temperature gradient; see Figure 2. The reaction heat produced should cause such a large temperature rise in the reactor that the mean temperature in the reactor is high enough to obtain full conversion, so:

$$
T_{99}=T_{\text {mean }}, \text { for } \Delta T_{a d}=\Delta T_{a d, \min } \ldots \ldots \ldots \ldots \ldots
$$

An expression to calculate $T_{99}$ is given by Equation (1). $T_{\text {mean }}$ is the average temperature in the catalyst bed (not in the inert sections of the reactor). To estimate $T_{\text {mean }}$, we approximate the temperature profiles by straight lines as illustrated in Figure 2, and obtain:

$$
T_{\text {mean }}=\frac{T_{m}+T_{i c}}{2} \text {. }
$$

where $T_{m}$ and $T_{i c}$ are the maximum temperature and the temperature at the boundary between inert and catalyst, respectively. These can be calculated as follows: 


$$
\begin{aligned}
& T_{m}=T_{i n}+\frac{L_{R}}{2} \frac{d T}{d z} \\
& T_{i c}=T_{i n}+x_{i c}\left(T_{m}-T_{i n}\right) .
\end{aligned}
$$

where $x_{i c}$ is the fraction of the reactor length filled with inert material, $L_{R}$ the reactor length and $d T / d z$ the temperature gradient. Since symmetric temperature profiles are assumed, see Figure 2, the temperatures at $z=0$ and $z=L_{R}$ are equal, and represented by $T_{i n}$. At $z=0$ during the first half of the cycle the temperature is the feed temperature, and in the second half of the cycle the temperature at $z=0$ is $\Delta T_{a d}$ higher, because the overall heat balance must be satisfied, see e.g. Van de Beld and Westerterp (1994a). So, averaged over one cycle $T_{i n}=T_{0}+0.5 \Delta T_{a d}$, but because $\Delta T_{a d}$ is very small it might neglected. Now, two cases can be distinguished:

$$
\begin{array}{ll}
\text { CaseI: } & T_{\text {in }}=T_{0} \\
\text { Case II : } & T_{\text {in }}=T_{0}+\frac{1}{2} \Delta T_{a d} \ldots \ldots \ldots \ldots \ldots \ldots
\end{array}
$$

Furthermore, a value of the temperature gradient is needed and Eigenberger and Nieken (1991), by using the equivalence with a reactor with counter-current heat exchange, found it can be approximated with the next expression:

$$
\frac{d T}{d z}=\frac{\Delta T_{a d}}{2 L} \frac{1}{\left(\frac{1}{P e_{h}}+\frac{1}{N T U_{h}}\right)}=\frac{\Delta T_{a d}}{2 L} P e_{p h} \ldots \ldots \ldots
$$

In Equation (7), the equivalence criterium as developed by Vortmeyer and Schaefer (1974) has been used. This criterium represents the mathematical equivalence between a homogeneous and heterogeneous heat transport model and can be written as:

$$
\frac{1}{P e_{p h}}=\frac{1}{P e_{h}}+\frac{1}{N T U_{h}}
$$

For $T_{\text {mean }} \geq T_{99}$ an autothermal process is possible with a high conversion of the contaminants. The critical adiabatic temperature rise is obtained if $T_{\text {mean }}$ equals $T_{99}$ as stated in Equation (3). An analytical expression is obtained by substitution of Equations (4)-(7) into Equation (3) and rearranging the expression:

For case I (see Equation (6)):

$$
\begin{gathered}
\Delta T_{a d, \text { min }}=\frac{8\left(T_{99}-T_{0}\right)}{\left(1+x_{i c}\right)} \cdot\left(\frac{1}{P e_{h}}+\frac{1}{N T U_{h}}\right) \\
\text { or } \frac{8\left(T_{99}-T_{0}\right)}{\left(1+x_{i c}\right) \cdot P e_{p h}} \ldots \ldots \ldots \ldots \ldots
\end{gathered}
$$

and for case II:

$$
\begin{gathered}
\Delta T_{a d, \min }=\frac{8\left(T_{99}-T_{0}\right)}{4+\left(1+x_{i c}\right)} \cdot\left(\frac{1}{P e_{h}}+\frac{1}{N T U_{h}}\right) \\
\quad \text { or } \frac{8\left(T_{99}-T_{0}\right)}{4+\left(1+x_{i c}\right) \cdot P e_{p h}} \ldots \ldots \ldots \ldots \ldots
\end{gathered}
$$

To validate Equations (8) and (9) we can study the extreme situations:

$-T_{99}=T_{0}$ : in that case $\Delta T_{a d, \min }=0$ and this is correct, because the reaction already proceeds at feed temperature and then for all concentrations a high conversion will be achieved.

- The effective axial dispersion coefficient equals zero or $P e_{p h}=\infty$ and $\Delta T_{a d, \min }=0$. This coincides with the calculations of Nieken (1993) that with $P e_{p h}=\infty$ blow-out of the reactor is not possible, even when no heat of reaction is released, because there is no heat dissipation. Of course, the cycle period should not exceed a certain maximum value.

The expressions given by Equations (8) and (9) can be used for a reactor operating under adiabatic conditions. An additional correction is necessary when severe radial heat losses occur. A higher concentration is required to counterbalance the heat losses:

$$
\Delta T_{a d, \min }=\Delta T_{a d, \min }^{*}-\Delta T_{l o s t} \ldots \ldots \ldots \ldots \ldots \ldots
$$

with $\Delta T_{a d \text {, } \min }^{*}$ the real value for non-adiabatic conditions. By assuming the temperature profile as depicted in Figure 2 the total heat losses over the reactor can be estimated, and expressed as an adiabatic temperature drop:

$$
\Delta T_{\text {lost }}=\frac{U_{w} a_{w}\left(T_{a v}-T_{w}\right) L_{R}}{u_{g}\left(\rho C_{p}\right)}=N T U_{w}\left(T_{a v}-T_{w}\right) \ldots
$$

The average temperature over the whole reactor including the inert sections is given by:

$$
T_{a v}=T_{i n}+\frac{L_{R}}{4} \frac{d T}{d z}
$$

Again, the temperature gradient is calculated with Equation (7) in which the adiabatic temperature rise is the apparent $\Delta T_{a d, \min }$. To be consistent we will use Equation (6) for the calculation of $T_{\text {in }}$ and, therefore the correction will be different for the two cases. Combination of Equations (10)(12), substituting Equations (6) $-(7)$, and assuming $T_{w}=T_{\text {in }}$ the following modified expressions are obtained:

$$
\text { Case I: } \Delta T_{a d, \min }^{*}=\Delta T_{a d, \min }\left(1+\frac{N T U_{w} P e_{p h}}{8}\right) \ldots
$$

$$
\text { Case II : } \Delta T_{a d, \min }^{*}=\Delta T_{a d, \min }\left(1+N T U_{w}\left(\frac{1}{2}+\frac{1}{8} P e_{p h}\right)\right)
$$

To validate Equations (13) and (14), assume $N T U_{w}=0$; this is equivalent with adiabatic conditions and the actual value of $\Delta T_{a d, \min }^{*}$ becomes equal to the apparent $T_{a d \min }$

So, the minimum amount of combustibles is influenced by the heat transport in the packed bed $\left(P e_{p h}\right)$, the kinetics of the oxidation reaction $\left(T_{99}\right)$, the amount of catalyst replaced by inert material $\left(x_{i c}\right)$, and the adiabaticity of the system or $N T U_{w}$. To validate the usability of this approach the influence of these parameters on $\Delta T_{a d, \min }$ is studied, both qualitatively and quantitatively.

In Figures 3A-3C predicted values of $\Delta T_{a d, \min }$ are compared to calculations with the full dynamic model. For the 

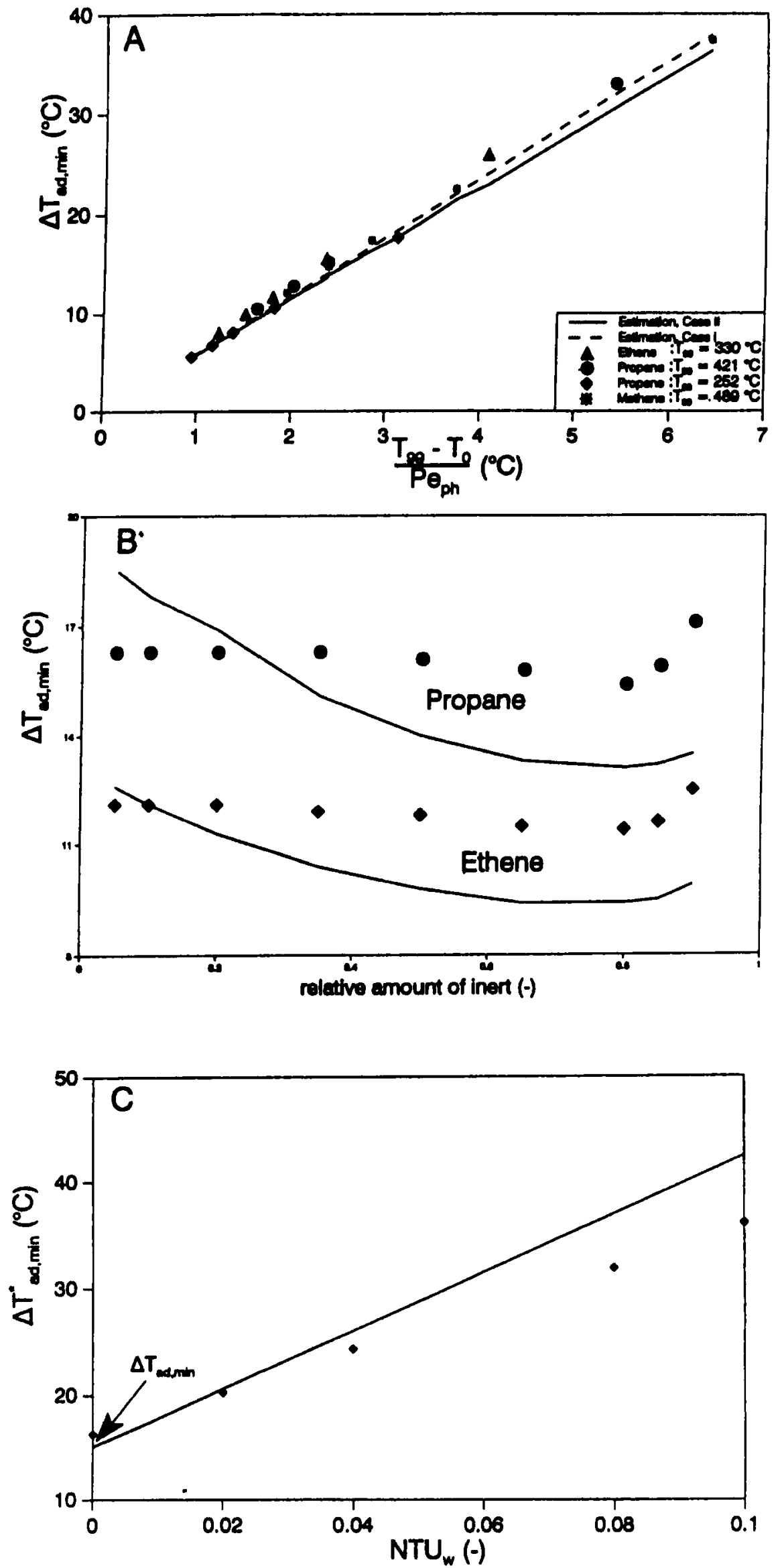

Figure 3 - Comparison of predictions of the minimum adiabatic temperature rise required (lines) and calculations (dots) with the full dynamic model. A: Influence of kinetic parameters and heat transport in the packed bed. B: Influence of the amount of catalyst replaced by inert material. C: Influence of radial heat losses. 
latter case, a trial and error method has been applied, because $T_{\text {ad,min }}$ can not be obtained directly from the dynamic simulations. For the calculations in Figure $3 \mathrm{~A}$, heat transport in the packed bed $\left(P e_{p h}\right)$ as well as the oxidation kinetics $\left(T_{99}\right)$ have been varied: $\Delta T_{a d, \text { min }}$ can be predicted satisfactorily. In Figure $3 \mathrm{~B}$, the length of the inert sections has been changed, keeping the total length of the reactor constant. Qualitatively similar behaviour is observed; only for short inert sections is the behaviour different. This is caused by the fact that for the real system below a certain value it does not make any difference whether this part is inert or filled with catalyst, because the temperature in the inlet section is too low for reaction. This also explains why for the dynamic simulations the same values of $\Delta T_{a d, \min }$ are found for small values of $x_{i c}$. The critical value of $x_{i c}$ is strongly related with the cycle period. In Figure $3 \mathrm{C}, \Delta T_{a d, \text { min }}$ is plotted as a function of $N T U_{w}$. For $N T U_{w}=0$, the reactor operates truly adiabatically; furthermore, $\Delta T_{a d, \min }$ increases with increasing $N T U_{w^{*}}$ At high values of $N T U_{w}$, the absolute difference between calculations and predictions becomes larger. This probably is due to the fact that the approximation of the temperature profile, as shown in Figure 2, is no longer valid.

\section{DIFFERENT METHODS TO INCREASE THE TEMPERATURE LEVEL} IN THE REACTOR

In practice, large variations might occur in the concentration, mixture composition and chemical character of the combustibles. After a change in composition and chemical character of the VOCs, the PSS temperature might be too low to achieve high conversions for all components in the new feed. Consequently, a method is needed to increase the temperature in the reactor rapidly and effectively. We will discuss some possible solutions to this problem:

(1) Increasing the feed temperature. To increase the bed temperature by, say, $\Delta T_{\text {bed }}$, it is necessary to increase the feed temperature by at least the same amount, whereas in most cases it must be larger. This requires a high energy input and it is inefficient. For control purposes it is too slow, because the entire bed has to be heated up by the hotter feed.

(2) Adding combustibles to the feed. Intuitively, this seems the most logical method to use, because it is simple to implement. However, a reactive combustible, added to the feed, will react already on the flanks of the temperature profile. This means that the increase in the maximum temperature in the centre of the bed is initially small. A component too difficult to oxidize with $T_{99} \gg$ $T_{\max }$ will not react at all or only with a very low conversion. Obviously such a component is not the optimal additive. So, it depends on the actual bed temperatures what is an effective additive. For strong variations we need a whole battery of additives, each one to cover a different temperature range.

(3) Installing an electrical heating device in the central part of the reactor. We need to increase the temperature in the hottest zone of the bed in order to oxidize also a less refractive component, that is in the centre of the bed. This might be achieved with an electrical heating device in the centre of the reactor. Such a device can increase the temperature very rapidly. Of course, the heat must be transferred from the heating device to the catalyst. This introduces an additional heat transport resistance in contrast to heat production by chemical reaction on the catalyst surface. Furthermore, it can be used for start-up purposes.

In due course, we will report on the experimental results with a such device; see Cunill et al. (1997).

(4) Adding combustibles in the central part of the reactor. Instead of using an electrical device as the energy source, we can use the heat of local combustion. A combustible can be used which already reacts at low temperatures, e.g. acetone. The drawbacks given under points 2 and 3 are avoided, but now lack of a good distribution of the contaminant over the entire cross-sectional area and the control of the system may cause difficulties.

(5) Permanent adding of a difficult to oxidize component, e.g. methane. With such a component, if ignited, the temperature level in the reactor will always be high and all other more refractive contaminants are surely converted. This is a rather energy consuming solution. For example, for the destruction of organic solvents -as in e.g. the dyeing or dry cleaning industry- the temperature level can be much lower, because normally these solvents can be easily oxidized at low temperatures. Furthermore, an increase in inlet concentration may be difficult to handle, because the catalyst may become rapidly overheated.

(6) Supply of a hot gas in centre of the reactor. This also seems to be an inefficient way to increase the temperature, since the heat capacity of gas is low compared to that of the bed.

We prefer to install an electrical heating device, because of its relative simple construction and its easy controllability. However, if a permanent heating support is required, because $\Delta T_{a d}$ is too low to maintain the PSS, an electrical heating device is too expensive. For such cases the fourth option, adding combustibles in the central part of the reactor, is a better choice. Depending on local regulations, below a certain value of $\Delta T_{a d}$ the reactor can be temporarily switched off, and in a well insulated RFR the high bed temperature will be maintained for a long period of time.

\section{PrEVENTING OF OVERHEATING OF THE CATALYST}

The temperature in the reactor should not exceed the maximum allowable catalyst temperature. This may occur when the concentration of contaminants becomes too high during a significant period of time. A short peak of a high concentration will not be a problem, since the heat capacity of the system is high and it will take time before the maximum temperature exceeds the limit. Furthermore, a reverse flow reactor exhibits some self-control with respect to the inlet concentration. For a low concentration, the reaction takes place in the central part of the reactor, so part of the catalyst bed is also used as a heat exchanger. If the inlet concentrations are increased, the temperature- and concentration profiles will move in the direction of the inlet and outlet of the reactor and a temperature plateau will develop; the actual increase of the maximum temperature is small, see Figure $4 \mathrm{~A}$ and $\mathrm{B}$, where from profile 1 to profile 2 only the length of the heat exchanging area changes. For higher inlet concentrations, full conversion is already obtained in the first layers of the catalyst bed; the length of the "heat exchanger" then equals the length of the inert sections and remains constant. From this point on, the maximum temperature will increase very rapidly with the inlet concentration. 

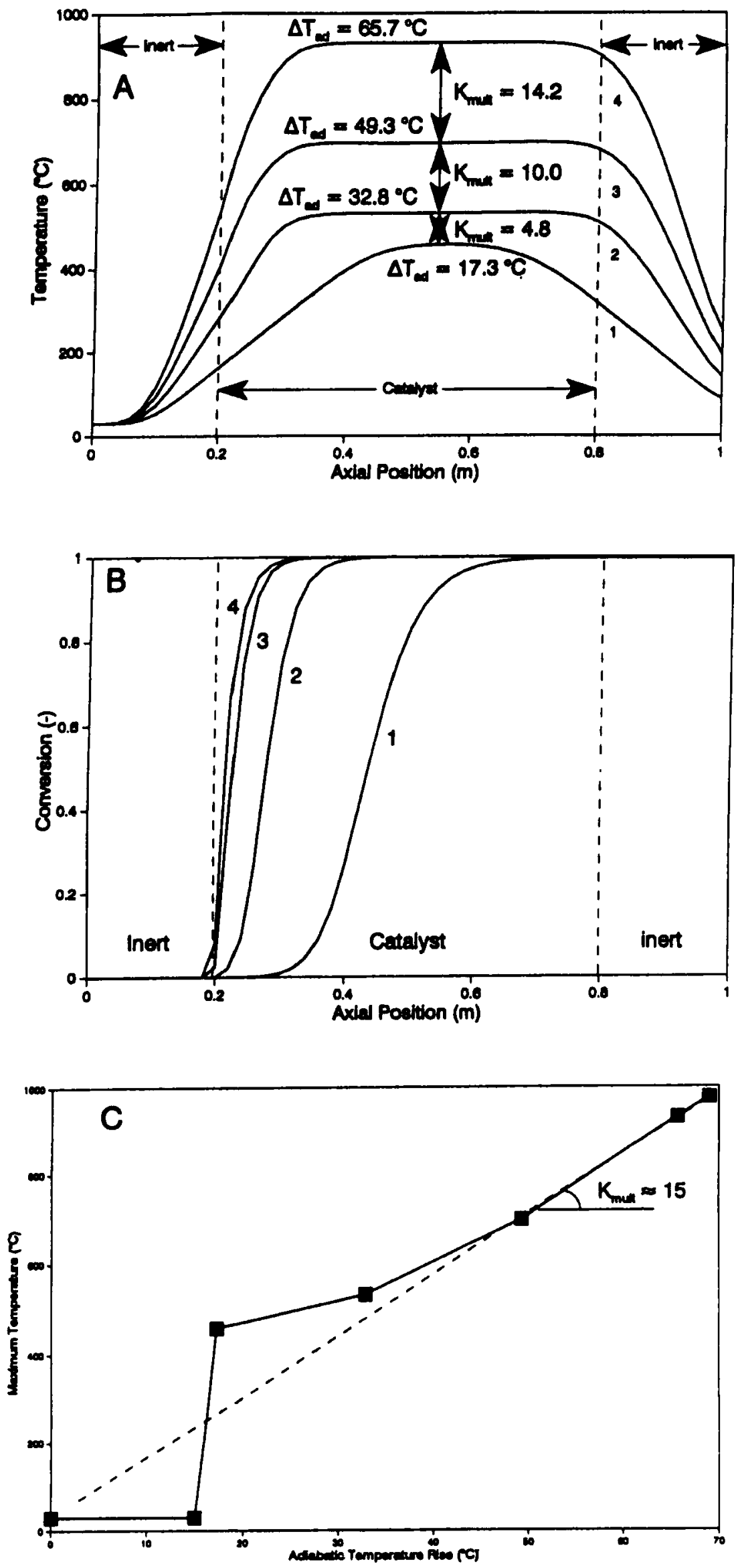

Figure 4-The complete oxidation of propane for different inlet concentrations. A. Axial temperature profiles in the PSS prior to flow reversal for different inlet concentrations propane. B. Axial conversion profiles in the PSS. C. Plateau temperature as a function of the adiabatic temperature rise. $t_{c}=400 \mathrm{~s} ; u_{g}=0.40 \mathrm{~m} / \mathrm{s}$. 


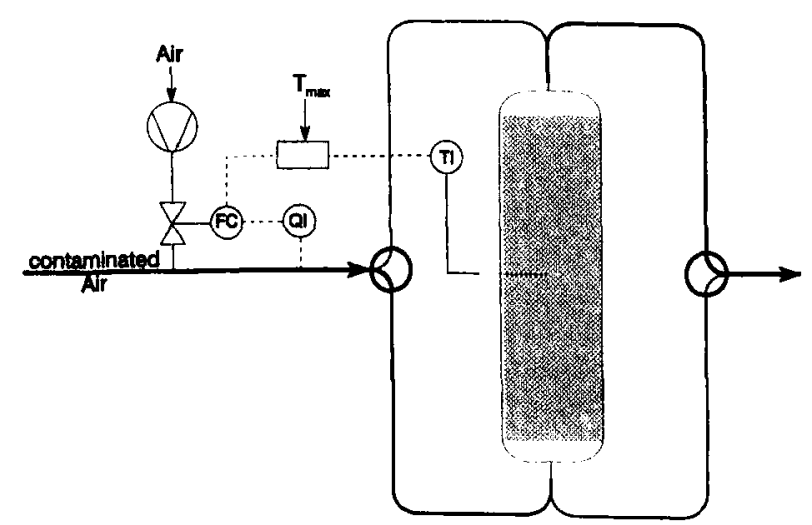

Figure 5-Control system to prevent overheating of the catalyst.

This is illustrated in Figure 4A, in the profiles 3 and 4. In Figures $4 \mathrm{~A}$ and $4 \mathrm{C}$ the local multiplying factor is given, which indicates the sensitivity of the maximum temperature for a change in inlet concentration.

$$
K_{\text {mult }, \text { local }}=\frac{\Delta\left(T_{\max }\right)}{\Delta\left(\Delta T_{a d}\right)}
$$

For a high $\Delta T_{a d}$ this factor becomes constant, because the length of the heat exchanging area becomes constant. This is also illustrated in Figure $4 C$, where $K_{\text {mult, local }}$ eventually reaches a value of 15 . When the reactor operates for a longer period of time with high concentrations of contaminants, overheating of the catalyst must be prevented. To this end, Nieken (1993) has proposed several methods for control of the maximum temperature like installing a heat exchanger, injection of cold gas in the centre of the reactor, withdrawal of hot gas from the centre or a combination of these methods. None of these methods is sufficiently general and efficacious. In our opinion, a simple and more adequate method is adding extra air to the feed, as illustrated in Figure 5. The total hydrocarbon concentration in the inlet is measured online, and only when the VOC concentration exceeds a certain limit during a certain period of time, is additional air is supplied to the feed. Consequently, the inlet concentration is lowered, which directly leads to a lower maximum temperature. Regretfully, the total flow rate increases significantly, which requires additional energy costs to overcome the higher pressure drop. Under industrial conditions the influence of the gas velocity itself on the plateau temperature is negligible; see Van de Beld and Westerterp (1995a).

\section{CATALYST AND INERT SECTIONS}

In a reverse flow reactor, the heat exchanger and reactor are combined in one apparatus. The inlet and outlet sections are used as heat exchangers and the reactions take place in the central, catalytic part. In this system, the length of the inert heat exchanging part is variable and automatically adjusted, as described in the previous section. The behaviour of the reactor is influenced by the amount of inert material and the length of the inert sections must be chosen carefully. One extreme is filling the whole system with inexpensive inert material. In that case, a thermal incineration process is obtained, which is known to occur at the much higher temperatures of thermal combustion compared to those of catalytic combustion. The temperature levels given in Figure 6A and B are: $T_{\text {thermal }}$ is the temperature level at
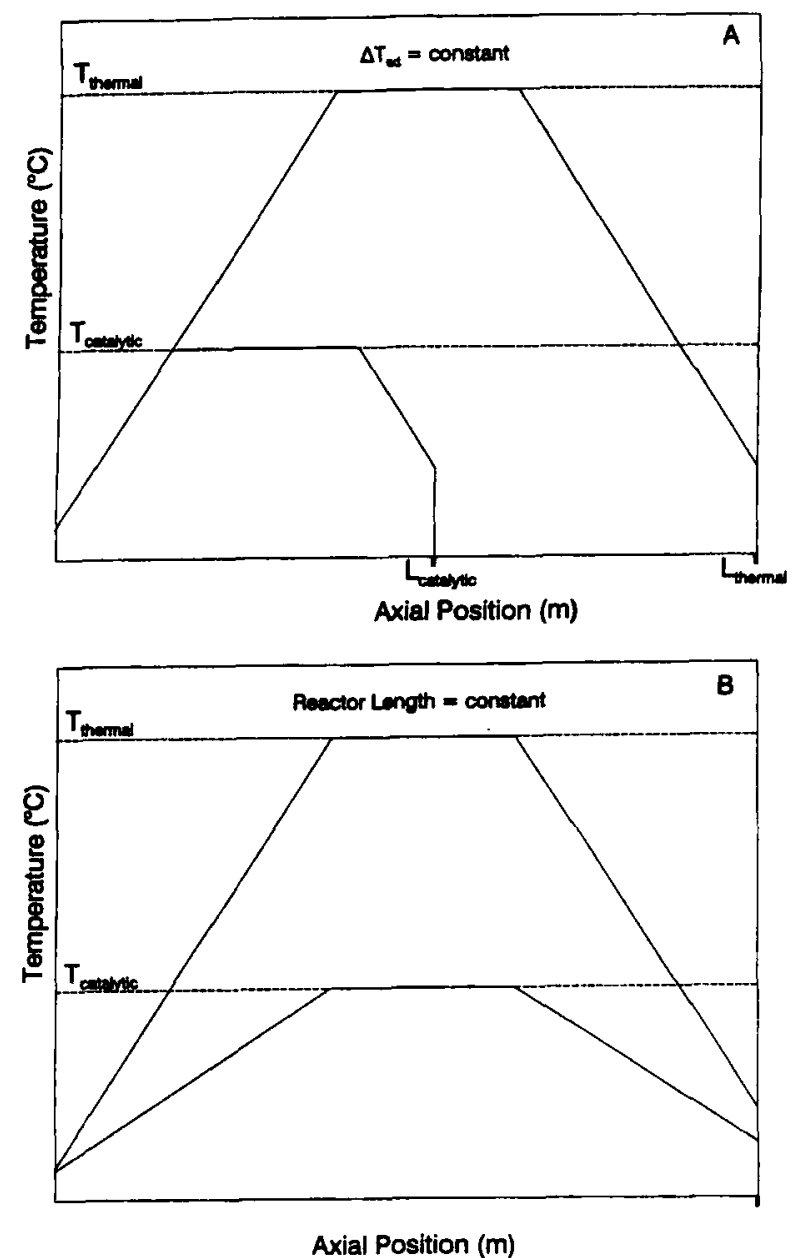

Figure 6 - Graphical representation of temperature profiles for the catalytic and thermal combustion process. A: inlet concentration is constant. B: reactor volume is constant.

which the homogeneous, and $T_{\text {catalytic }}$ at which the heterogeneous reaction takes place. The higher temperature levels can be reached by:

a) installing more heat exchanging area. The result is that for a thermal system the apparatus volume increases significantly. This is illustrated in Figure 6A, where it is assumed that the required reaction zone remains equal.

b) much steeper temperature gradients, to which end the inlet concentrations must be increased, see Equation (7). So, in a reactor with the same volume as a catalytic system an autothermal process is possible with thermal combustion, but the inlet concentrations must be significantly higher; see Figure 6B.

The thermal incineration system, however, is an interesting alternative for high VOC concentrations or for the purification of exhaust air containing catalyst poisons.

The other extreme situation is filling the whole reactor with catalyst. The inlet and outlet parts will always be cold and without reaction. The self-controlling behaviour with respect to the inlet concentration -as described before- is enlarged for a larger catalyst bed. In practice, inert sections will be often installed for economical reasons. Moreover, the geometric and thermophysical properties of the inert layer can be chosen to be different from those of the catalyst. The length of the total bed should be based on the maximum allowable pressure drop at the highest flow rate expected. 


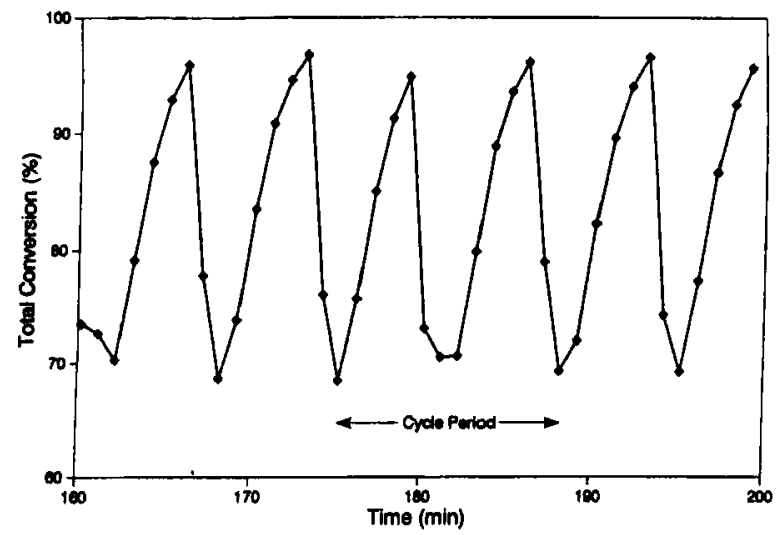

Figure 7 - Total hydrocarbon conversion in the reactor outlet as a function of time. $C_{\text {methanol }}=0.18 \mathrm{vol} \% ; C_{\text {ethene }}=0.095 \mathrm{vol} \% ; t_{c}=$ $800 \mathrm{~s} ; u_{g}=0.40 \mathrm{~m} / \mathrm{s}$.

The cycle time is chosen such that the heat front will travel a certain distance, but will not pass the boundary between the inert and catalytic layers. This can be a tool to optimize heat transport properties and minimize the pressure drop, see e.g. Sapundzhiev et al. (1990). Haynes et al. (1995) developed a design equation to determine the optimal length of the inert layers, by determining the length where the temperature is always too low for reaction, and therefore the reactions will not take place in this region, so here the catalyst can be replaced by inert material.

There is also a special constraint to the quality of the inert material, as illustrated in Figure 7, where the total conversion is shown as a function of time for an experiment with ethene and methanol as contaminants. For details of the experimental installation we refer to Van de Beld et al. (1994a). For only ethene, the conversion is above $98 \%$ over the whole cycle. With methanol also in the polluted air we observed a change in conversion during the cycle reaching a minimum in the total conversion of around $70 \%$. Although methanol is easy to oxidize, after flow reversal the conversion of methanol is low, because it adsorbs in large quantities in the inlet section of the reactor on the cold inert particles of $\alpha-\mathrm{Al}_{2} \mathrm{O}_{3}$. After flow reversal, this part of the reactor is heated up and eventually the methanol desorbs and leaves the reactor unconverted. So, part of the methanol never reaches the catalyst layer to be burnt. This adsorption is a serious handicap for applying a reverse flow reactor in e.g. dyeing industry, since organic solvents like ethers, aldehydes or alcohols are expected to exhibit a similar behaviour. This problem can be solved for such kind of contaminants by designing the system with no feed bypass, e.g. using three reactors, see e.g. Eigenberger (1992). In this case, the time constant of desorption must be much smaller then the cycle time. For the experiments in Figure 7, this was not the case, because the conversion still was changing significantly at the end of the cycle. To minimize or to avoid slip of such components, an inert material must be chosen with a very low or no adsorption capacity, e.g. glass or steel.

\section{Summary and conclusions}

Aspects important for the operation of a reverse flow reactor (RFR) for the purification of polluted air have been discussed and special attention paid to the operation of the reactor for strongly varying process conditions. A simple, empirical method is presented to determine the minimum

operating temperature required to warrant full conversion of contaminants. The inlet concentration of the contaminants should be high enough to maintain this minimum temperature in the reactor. This minimum inlet concentration is represented by the critical minimum adiabatic temperature rise $\Delta T_{a d, \text { min }}$. An analytical expression has been derived to predict $\Delta T_{a d \text {,min }}$; it has been found to depend on the reaction kinetics, the heat transport characteristics of the packed bed, the amount of catalyst replaced by inert material and the adiabaticity of the reactor. The cycle period has a negligible influence, provided that it is not too large such that too much heat is removed from the reactor.

For strongly varying process conditions we can distinguish two cases: 1) the temperature in the reactor is too low and the conversion is too small, and 2) the bed temperature exceeds the maximum allowable temperature. For the first case, several suggestions were made to increase the bed temperature rapidly. In our opinion, the best method is to install an electrical heating device in the centre of the bed. For the second case we recommend to dilute by adding more air to the feed. The result is a lower inlet concentration and a lower maximum temperature in the PSS.

Choice of materials for the inert sections is important. To obtain a high conversion, it is important to avoid adsorption of the contaminants on the cold particles.

\section{Acknowledgement}

These investigations were supported by The Netherlands' Foundation for Chemical Research (SON), with financial aid from The Netherlands' Technology Foundation and DSM.

\section{Nomenclature}

$a_{w}=$ specific internal wall area per unit $\quad \mathrm{m}^{2} / \mathrm{m}^{3}$

reactor volume

$C_{p} \quad=$ specific heat capacity

$E_{a c t} \quad=$ activation energy

$k_{\infty} \quad=$ pre-exponential factor

$K_{\text {mutt }} \quad=$ multiplying factor, see Equation (15)

$L_{R} \quad=$ reactor length

$\mathrm{kJ} / \mathrm{kg} \cdot \mathrm{K}$

$\mathrm{kJ} / \mathrm{mol}$ $\mathrm{mol} / \mathrm{Pa} \cdot \mathrm{s} \cdot \mathrm{m}^{3}$ $-$

$N T U_{h}=\frac{\alpha a_{p}(1-\epsilon) L_{R}}{\left(\rho C_{p}\right)_{g} u_{g}}, \underset{\text { bed }}{\text { number of heat transfer units in the }}$

$N T U_{w}=\frac{U_{w} a_{w} L_{R}}{\left(\rho C_{p}\right)_{g} u_{g}}$, number of heat transfer units at the wall

$P e_{h} \quad=\frac{u_{g}\left(\rho C_{p}\right)_{g} L_{R}}{\in \lambda_{e f f}}, \begin{aligned} & \text { Peclet number for heat } \\ & \text { (heterogeneous model) }\end{aligned}$

$P e_{p h}=\frac{u_{g}\left(\rho C_{P}\right)_{g} L_{R}}{\lambda_{a x}}, \begin{aligned} & \text { Peclet number for heat } \\ & \text { (pseudo-homogeneous model) }\end{aligned}$

$R \quad=$ gas constant

$T \quad=$ temperature

$T_{0} \quad=$ feed temperature

$T_{99}=$ minimum temperature for $99 \%$ conversion; see Equation (1)

$T_{a v} \quad=$ mean temperature in whole reactor

$T_{i c}^{a v} \quad=$ temperature at boundary between catalyst and inert

$T_{\text {in }} \quad=$ temperature at inlet; see Equation (6)

$T_{m} \quad=$ maximum temperature in the reactor

$T_{\text {mean }}=$ mean temperature in catalytic bed

$T_{w} \quad=$ temperature surroundings

$u_{g} \quad=$ superficial gas velocity

$U_{w} \quad=$ overall heat transfer coefficient
$\mathrm{kJ} / \mathrm{mol} \cdot \mathrm{K}$

$\mathrm{K}$

$\mathbf{K}$

$\mathbf{K}$

$\mathrm{K}$

K

K

K

$\mathbf{K}$

$\mathrm{K}$

$\mathrm{m} / \mathrm{s}$

$\mathrm{kW} / \mathrm{m}^{2} \cdot \mathrm{K}$ 
$x_{i c} \quad=$ fraction inert material in the reactor

$z \quad=$ axial position

\section{Greek letters}

$\alpha=$ interparticle heat transfer coefficient

$\Delta T_{a d} \quad=$ adiabatic temperature rise

$\Delta T_{a d, \min }=$ minimum adiabatic temperature rise

$\Delta T_{a d, \min }^{*}=$ minimum adiabatic temperature rise corrected for heat losses

$\lambda_{a x}=$ effective axial thermal conductivity (pseudo-homogeneous model)

$\lambda_{\text {eff }}=$ effective axial thermal conductivity (heterogeneous model)

$\mathrm{kW} / \mathrm{m}^{2} \cdot \mathrm{K}$

K

K

K

$\mathrm{kW} / \mathrm{m} \cdot \mathrm{K}$

$\mathrm{kW} / \mathrm{m} \cdot \mathrm{K}$

\section{References}

Anonymous, "Hydrocarbon Processing's Environmental Processes '93", Hydroc. Proc., August, 67-105 (1993).

Beld, L. van de and K. R. Westerterp, "Air Purification by Catalytic Oxidation in a Reactor with Periodic Flow Reversal", Chem.Eng. Technol. 17, 216-226 (1994a).

Beld, L. van de, R. A. Borman, O. R. Derkx, B. A. A. van Woezik, and K. R. Westerterp, "Removal of Volatile Organic Compounds from Polluted Air in a Reverse Flow Reactor", Ind. Eng. Chem. Res. 33, 2946-2956 (1994b).

Beld, L. van de, M. P. G. Bijl, A. Reinders, B. van der Werf and K. R. Westerterp, "The Catalytic Oxidation of Organic Contaminants in a Packed Bed Reactor", Chem. Eng. Sci., 49, $4361-4373$ (1994c).

Beld, L. van de and K. R. Westerterp, "Decontamination of Polluted Air in a Reverse Flow Reactor: Comparison of Model Simulations and Experiments", AIChE J., 42, 1139-1148 (1996).
Boreskov, G. K., Yu. Sh. Matros and A. G. Ivanov, "Utilization of the Heat of Catalytic Combustion of Low-Caloric Gaseous Fuel Mixtures by Reversing the Direction of their Input", Doklady Chem. Tech., 288, 55-59 (1986).

Cunill, F., L. van de Beld, K. R. Westerterp, "Catalytic Combustion of Very Lean Mixtures in a Reverse Flow Reactor using an Internal Electrical Heater, accepted for publication in Ind. Eng. Chem. Res. (1997).

Eigenberger, G., "Fixed-Bed Reactors", in "Ullmann's Encyclopedia of Industrial Chemistry, Fixed-Bed Reactors", Vol. B4, VCH Publishers Inc., Weinheim, Germany (1992), pp. 199-238.

Haynes, T. N., C. Georgakis and H. S. Caram, "The Design of Reverse Flow Reactors for Catalytic Combustion Systems", Chem. Eng. Sci. 50, 401-416 (1995).

Matros, Yu. Sh., "Mathematical Modelling of Chemical ReactorsDevelopment and Implementation of Novel Technologies", Angew. Chem. Int. Ed. Engl. 29, 1235-1245 (1990).

Nieken, U., "Abluftreinigung in Katalytischen Festbettreaktoren bei Periodischer Strömungsumkehr", VDI-Fortschrittberichte, reihe 3, nr. 328 (1993).

Sapundzhiev, C., G. Grozev and D. Elenkov, "Influence of Geometric and Thermophysical Properties of Reaction Layer on Sulphur Dioxide Oxidation in Transient Conditions", Chem. Eng. Technol. 13, 131-135 (1990).

Manuscript received July 24, 1995; revised manuscript received May 13, 1997; accepted for publication May 13, 1997. 